\title{
BMJ Open Partners for the optimal organisation of the healthcare continuum for high users of health and social services: protocol of a developmental evaluation case study design
}

Catherine Hudon, ${ }^{1}$ Maud-Christine Chouinard, ${ }^{2,3}$ Martine Couture, ${ }^{4}$ Astrid Brousselle, ${ }^{5}$ Eva Marjorie Couture, ${ }^{1,3}$ Marie-France Dubois, ${ }^{5}$ Martin Fortin, ${ }^{1,3}$ Tobias Freund, ${ }^{6}$ Christine Loignon, ${ }^{1}$ Jean Mireault, ${ }^{7}$ Pierre Pluye, ${ }^{8}$ Pasquale Roberge, ${ }^{1}$ Charo Rodriguez ${ }^{8}$

To cite: Hudon $\mathrm{C}$, Chouinard M-C, Couture M, et al. Partners for the optimal organisation of the healthcare continuum for high users of health and social services: protocol of a developmental evaluation case study design. BMJ Open 2014;4:e006991. doi:10.1136/bmjopen-2014006991

- Prepublication history for this paper is available online. To view these files please visit the journal online (http://dx.doi.org/10.1136/ bmjopen-2014-006991).

Received 22 October 2014 Accepted 11 November 2014

CrossMark

For numbered affiliations see end of article.

\section{Correspondence to}

Professor Catherine Hudon; Catherine.Hudon@

USherbrooke.ca

\section{ABSTRACT}

Introduction: Case management allows us to respond to the complex needs of a vulnerable clientele through a structured approach that promotes enhanced interaction between partners. Syntheses on the subject converge towards a need for a better description of the relationships between programmes and their local context, as well as the characteristics of the clienteles and programmes that contribute to positive impacts. The purpose of this project is thus to describe and evaluate the case management programmes of four health and social services centres in the Saguenay-LacSaint-Jean region of Québec, Canada, in order to inform their improvement while creating knowledge on case management that can be useful in other contexts.

Methods and analysis: This research relies on a multiple embedded case study design based on a developmental evaluation approach. We will work with the case management programme for high users of hospital services of each centre. Three different units of analysis will be interwoven to obtain an in-depth understanding of each case, that is: (1) health and social services centre and local services network, (2) case management programme and (3) patients who are high users of services. Two strategies for programme evaluation (logic models and implementation analysis) will guide the mixed data collection based on qualitative and quantitative methods. This data collection will rely on: (1) individual interviews and focus groups; (2) participant observation; (3) document analysis; (4) clinical and administrative data and (5) questionnaires. Description and comparison of cases, and integration of qualitative and quantitative data will be used to guide the data analysis.

Ethics and dissemination: The study protocol was approved by the Ethics Research Boards of the four health and social services centres (HSSCs) involved. Findings will be disseminated by publications in peerreviewed journals, conferences, and policy and practice partners in local and national government.

\section{Strengths and limitations of this study}

- The case study and the developmental evaluation approach are adaptable to the complexity and evolution of the context.

- Various strategies will be used to facilitate good validity and to help us determine qualitative impacts attributable to the programme: ${ }^{24}$

- Triangulation of data sources and evaluators to deepen our understanding of the question;

- Reflexive process and evaluation minded all along the data interpretation phase;

- Integration of qualitative and quantitative data allowing us to directly question people concerned on other aspects potentially influencing results.

- The study will be carried out in only one region of Québec. However, multiple case studies will allow us to ensure transferability to other contexts, through the theoretical enlightenment provided and the reproducibility of observations in many cases. ${ }^{27}$

\section{INTRODUCTION}

Much like other industrialised countries, ${ }^{1}{ }^{2}$ the Health Services Research Institute observed that close to $80 \%$ of the costs of healthcare at the Canadian level is attributable to $10 \%$ of the population. ${ }^{3}$ Many of these people frequently use hospital services for increasingly complex health needs ${ }^{4-6}$ arising from such factors as multimorbidity, psychiatric comorbidities and psychosocial issues, or a combination of these factors. ${ }^{5} 78$ Requiring care and services from many partners in the health and social services care system as well as the community network, these high users are more at risk of encountering difficulties in the integration of care, ${ }^{9}$ and more at risk for incapacity and mortality. ${ }^{10}$ Faced with this issue, case management $(\mathrm{CM})$ is increasingly being 
recognised internationally as an appropriate intervention to improve satisfaction and quality of life, ${ }^{11}$ and to reduce costs associated with high users of services..$^{1}{ }^{4}{ }^{11-16} \mathrm{CM}$ allows better response to the complex needs of a very vulnerable clientele through a structured approach that promotes enhanced interaction between partners of the health and social services system as well as with the community network.

$\mathrm{CM}$ is defined as a dynamic and systematic collaborative approach to ensure, coordinate, and integrate care and services for a clientele. An intervention geared towards interdisciplinarity in which a key practitioner or navigator (nurse, social worker or others) evaluates, plans, implements, coordinates and prioritises services based on people's need in close collaboration with concerned partners. ${ }^{17} \mathrm{CM}$ emphasises four main components: (1) in-depth evaluation of the person's needs and resources; (2) establishment and follow-up of an individualised services plan that is person-centred; (3) coordination of services between partners to improve services integration; and (4) self-management support of the person and his or her family. ${ }^{18} 19$

Although results appear correlated with programme intensity, ${ }^{12}$ characteristics of $\mathrm{CM}$ programmes present much variability in regard to, for example, their implementation contexts, targeted clienteles and duration of follow-up. ${ }^{20}{ }^{21}$ Syntheses on the subject converge towards a need for a better description of the CM programmes and the relationships between programmes and their local context, as well as the characteristics of the clienteles and programmes that contribute to positive impacts. ${ }^{20-22}$

In 2004, the creation of local services networks (LSN) in Québec aimed to bring services closer to the population and to make them more accessible and better integrated. At the heart of each LSN, an establishment called a health and social services centre (HSSC), including hospital, community and long-term services, acts as the basis or foundation for the LSN ensuring access, continuity, coordination and quality of the services intended for the population of its local territory. ${ }^{23}$ In 2008, the Saguenay-Lac-Saint-Jean health and social services agency appointed the six HSSCs of its territory to deploy CM programmes for high users of hospital services.

The aim of this project is thus to describe and evaluate the CM programmes of four HSSCs in the region in order to inform their improvement while creating knowledge on CM that can be useful in other contexts. ${ }^{24}$ Specifically, this study, funded by the Canadian Institutes of Health Research (CIHR) within its Partnerships for Health System Improvement programme, aims to answer the following questions over the course of three evaluation cycles while providing feedback to key decisionmakers over the 3 years of the project: (1) What are the different components of the CM programme of each HSSC: their structure, their actors (targeted clientele and practitioners), their operating process and their predictable effects? (2) What are the strengths and aspects to improve of each programme from the perspective of the concerned actors in view of a better services integration? (3) What characteristics of the clientele and the CM programmes contribute to positive impacts on use of services, quality of life, patient activation and patient experience with care?

\section{METHODS AND ANALYSIS}

\section{Conceptual framework}

The research question as well as the data collection (interview and discussion guides) and analysis will rely on the conceptual framework suggested by Chaudoir et $a l^{25}$ to guide research on the implementation of innovations. This framework proposes five broad categories of factors to consider in the evaluation of the implementation of an innovation (programme), that is: (1) environmental factors; (2) organisational factors; (3) factors related to the practitioners; (4) factors related to the patients and (5) programme-related factors. Environmental factors refer to the larger context in which the organisation evolves, such as, for example, their mandates and allocated funds. Organisational factors include different aspects associated with the organisation in which the programme is implemented, such as organisational culture, type of leadership and climate. Factors associated with the practitioners represent the characteristics of these individuals who interact with patients within this programme, for example, attitudes towards the innovations or capacity in adapting to change. The factors related to the patients correspond to the characteristics of these patients that can influence the results of the programme, such as motivation to get involved in the programme. Finally, factors linked to the programme represent the aspects of the implemented programme. These five broad categories of factors will be used to guide us in the identification of characteristics that can potentially contribute to the impact.

The integration of CM services into each LSN will be examined according to the integrated care model recently suggested in England. ${ }^{26}$ This model proposes six essential dimensions of services integration based on patient experience: (1) consideration of patient and family needs; (2) communication with the patient and between practitioners; (3) access to information; (4) involvement in decision-making; (5) care planning; and (6) transitions between various health professionals and practitioners.

\section{Research design}

This longitudinal research relies on a multiple embedded case study ${ }^{27}$ design based on a developmental evaluation approach (figure 1). ${ }^{28}{ }^{29}$ Multiple case study is preferred as this design is well adapted to respond to a research question focused on the 'how' in a complex system (LSN), and in dynamic and varied contexts at the time of the study. ${ }^{27}{ }^{30}$ We will work with four cases, the 'case' being the CM programme for high users of 
Figure 1 Research design and project outline. CM, case management; HSSC, health and social services centre; QUAL, qualitative data; QUAN, quantitative data.

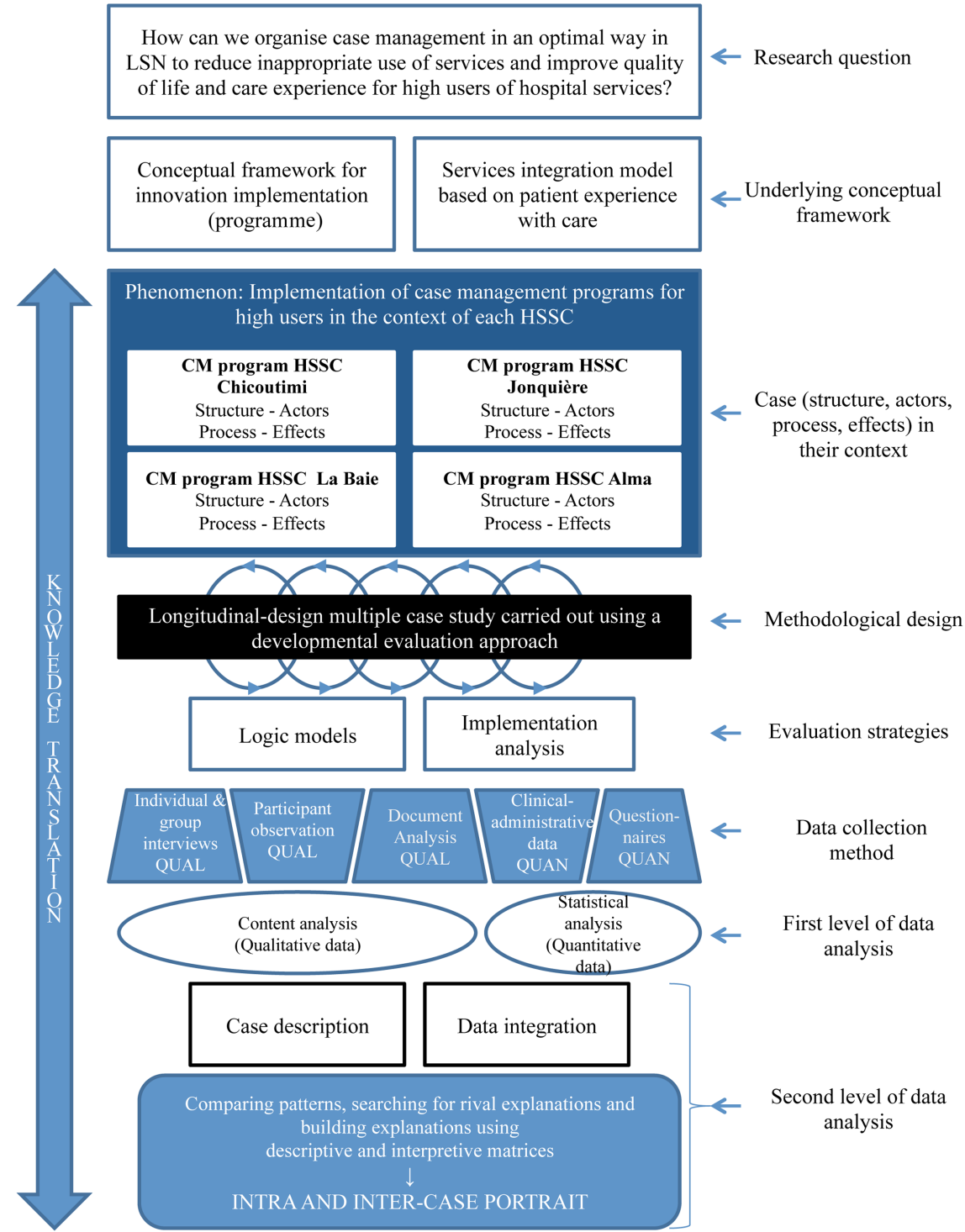

How can we organise case management in an optimal way in LSN to reduce inappropriate use of services and improve quality $\leftarrow$ Research question and care experience for high users of hospital services?

\begin{tabular}{c|c|c}
$\begin{array}{c}\text { Conceptual framework for } \\
\text { innovation implementation } \\
\text { (programme) }\end{array}$ & $\begin{array}{c}\text { Services integration model } \\
\text { based on patient experience } \\
\text { with care }\end{array}$ & $\begin{array}{c}\text { Underlying conceptual } \\
\text { framework }\end{array}$ \\
\hline
\end{tabular}
high users in the context of each HSSC

CM program HSSC Case (structure, actors, ocess, effects) in

CM program HSSC AIma

Structure - Actors Process - Effects

st level of data analysis

devel of data analysis

ollaboratively asking evaluative questions and collecting data allowing for feedback, and to support decisionmaking and modifications to be made to improve the programme. $^{32}$ Considered as a rigorous evaluative approach, it allows for the required flexibility in a context of evolving programmes in real clinical settings. ${ }^{32} 33$ According to this approach, the three main roles of the researchers in the team are to: (1) accompany the team to facilitate the project's evolution; (2) collect qualitative and quantitative data; and (3) ensure continuous feedback of results to the Director-generals and programme directors and to the committees that are designated to organise services for high users, committees that will be identified with the Director-general of each HSSC. ${ }^{33}$

\section{Data collection strategies associated with each research question (primary and secondary outcomes)}

Two strategies for programme evaluation (logic models and implementation analysis) ${ }^{34}$ will guide the mixed data collection. This data collection will rely on five methods (three qualitative and two quantitative) explained further 
in the text. A database will be created in order to organise the data collected during the case study. It will contain the raw data to be used to write the case history, but will remain distinct and be used by an independent reviewer if need be, thus improving the reliability of the study. ${ }^{27}$ The database will include: field notes, collected documents and other material (verbatim, observation notes, quantitative data). Reliability will also be ensured by different strategies ${ }^{27}$ to maintain an explicit chain of evidence: (1) the case history will refer to the pertinent citations in the database; (2) the database will contain sufficient information on the data collection; (3) the data collection will follow the procedures announced.

\section{Question 1 (secondary outcome)}

What are the components of the CM programme of each HSSC: structure, actors, operating process and predictable outcomes?

To answer the first question, the logic model for the CM programme of high users of services of each HSSC will be described ${ }^{35}$ to present its structure, its actors (targeted clientele and professionals/practitioners) and its processes, and to illustrate what it aims to accomplish (its effects/outcomes). ${ }^{36}$ To be coherent with developmental evaluation, these models will be updated in years 2 and $3 .^{33}$ The data collection methods will involve interviews and focus groups with the various stakeholders (table 1) and analysis of the documents related to the implementation of each programme.
Question 2 (secondary outcome)

What are the strengths and areas for improvement of each programme from the concerned actors' point of view in the perspective of a better integration of services?

\section{Question 3 (primary outcome)}

What characteristics of the clientele and CM programmes contribute to a positive impact on use of services, quality of life, patient activation and patient experience of care?

To answer questions 2 and 3, an implementation analysis will focus on the internal dynamics of the programmes by examining the influence of the interaction between each programme and its implementation context in an attempt to explain the variations observed in its effects. ${ }^{34}$ Implementation analysis is "particularly important when the intervention analysis is complex and composed of sequential elements with which the context may interact in different ways." ${ }^{34}$ The case study design is totally appropriate for the analysis of complex intervention implementations. ${ }^{34} 37$ The logic models formulated in question 1 will be compared to identify the common and distinct aspects between HSSCs, allowing us to hypothesise on the characteristics potentially having an impact on use of services, quality of life and care experience, hypotheses that will be explored in the implementation analysis. The conceptual framework presented previously will also be used to identify significant characteristics. In addition, implementation analysis will address conditions for transferability of programmes to

Table 1 Type of interviews planned according to stakeholder category

\begin{tabular}{|c|c|c|}
\hline Stakeholder category & $\begin{array}{l}\text { Individual interviews } \\
\text { (total number of interviews in each HSSC) }\end{array}$ & $\begin{array}{l}\text { Group discussions } \\
\text { (number of groups of } 6-10 \\
\text { participants in each HSSC) }\end{array}$ \\
\hline $\begin{array}{l}\text { Decision-makers and } \\
\text { managers }\end{array}$ & $\begin{array}{l}\text { Director-general Agency (1) } \\
\text { Director-general HSSC (4) } \\
\text { - Programme directors CM (4) } \\
\text { - Programme managers CM (4) }\end{array}$ & $\begin{array}{l}\text { Programme coordinators with links } \\
\text { to CM programmes (4) }\end{array}$ \\
\hline Case managers & - Practitioners playing an important role in CM (12) & \\
\hline Medical teams & $\begin{array}{l}\text { Directors of professional services (4) } \\
\text { Presidents of the physicians, dentists and } \\
\text { pharmacists council (4) }\end{array}$ & $\begin{array}{l}\text { Executive members of the } \\
\text { physicians, dentists and } \\
\text { pharmacists council (4) } \\
\text { Territorial tables on primary care } \\
\text { medicine (4) } \\
\text { Territorial tables on specialised } \\
\text { medicine (4) }\end{array}$ \\
\hline $\begin{array}{l}\text { Professional teams (nurses, } \\
\text { social workers, others) }\end{array}$ & & $\begin{array}{l}\text { In close contact with frequent users } \\
\text { in HSSC (4) } \\
\text { In close contact with frequent users } \\
\text { in the community (primary care) (4) }\end{array}$ \\
\hline $\begin{array}{l}\text { Pharmacists and community } \\
\text { organisations }\end{array}$ & & $\begin{array}{l}\text { Community pharmacists (4) } \\
\text { - Community organisations (4) }\end{array}$ \\
\hline Patients and family caregivers & $\begin{array}{l}\text { In years } 2 \text { and } 3 \text { : frequent users having } \\
\text { experienced the most and the least improvement } \\
\text { in quality of life (32) }\end{array}$ & $\begin{array}{l}\text { Frequent users of services (4) } \\
\text { Family caregivers (4) }\end{array}$ \\
\hline
\end{tabular}


other contexts while providing information on the characteristics of these contexts more likely to generate positive impacts. ${ }^{34}$

\section{Data collection methods}

Answers to questions 2 and 3 (implementation analysis) will be obtained through a mixed data collection based on the five following methods:

1. Individual interviews and focus groups (qualitative data)

The main actors involved in CM and the care continuum of high users of services will be engaged through purposive sampling ${ }^{38}$ in each HSSC, at the beginning of years 1, 2 and 3. Various strategies were suggested by the HSSC partners to promote participation and facilitate exchanges: integration of discussions into existing meetings; planning discussions over a meal if and when appropriate; sending personalised invitations through leaders in the areas of interest. All individual and group interviews (table 1), conducted using interview guides composed of open questions adapted to the group of interest, will be audio recorded and transcribed verbatim. The interview guides will address the five main categories of factors to consider in the implementation of a programme (described in the conceptual framework). Patient experience with care will be operationalised according to the six dimensions presented in the model of services integration. Data saturation is not the goal for each group, but the diversity of actors engaged will provide a complete representation of each case. ${ }^{39}$ In addition to the group discussion planned with the high users of services in each HSSC, additional samples will be recruited in years 2 and 3 for individual interviews among people who have had the most and least improvement in quality of life over a 1-year period (total $n=8$ in each HSSC). These interviews will allow us to examine the factors that contributed to or hindered an impact on this variable.

2. Participant observation (qualitative data)

The developmental evaluation approach ${ }^{28}$ proposes the active participation of the research team (research assistants and principal investigators) within the partner HSSC. This participant observation will contribute to keeping the HSSC informed periodically of the results of the evaluative process and to observe changes occurring in the field ${ }^{40}$ to better assess transformation processes. ${ }^{33}$ Participant observation will take place during quarterly meetings (principal investigators) with the Director-generals, CM programme directors and two clientele representatives in the HSSC and during meetings of the committees designated to organise care for high users (research assistants). Data will be collected using a logbook and field notes. ${ }^{38}$

3. Document analysis (qualitative data)

The analysis of documents on the subject of programme implementation will serve to corroborate and complete the information obtained through the other data collection methods. ${ }^{40}$ Two main sources of documents will be used: documents on the CM programme of high users of services and meetings records of the committees designated with the organisation of care for high users.

4. Clinical and administrative data (quantitative)

Utilisation of services will be considered from an organisation perspective. This way, the number of high users of emergency and hospitalisation services and the ratio of high user visits/total visits will be determined monthly for each HSSC using the already operational Magic Chronique computer application, which uses interfaces that are similar in all four HSSC. In the absence of a consensus definition of frequent users in the literature, the one retained at a regional scale will be used (six visits or more to the emergency room in the past year or 3 hospitalisations or more). The ratio compiling all high user visits/total visits will also be determined for each HSSC. Quality of data will be controlled using an integrated model of information quality and using a series of algorithms for the validation of data. These data will also be collected retrospectively for all HSSCs (on a monthly basis in the year preceding the start-up of the project).

5. Questionnaires (quantitative data)

Each project year will coincide with the recruitment of the new cohort of high users in the CM programme of each HSSC for a period of 1 year. The French-language questionnaires, in which metrological qualities are well documented and adequate, will be administered, following informed consent, to all persons (100 patients from the HSSC of Chicoutimi and HSCC of Jonquière, and 75 patients from the HSSC of Alma and HSSC of La Baie) at entry into the CM programme (sociodemographic questionnaire, health literacy, patient activation, multimorbidity and quality of life) and at 6 months and 1 year (quality of life). The sociodemographic questionnaire will assess age, sex, income and education of the participants. Literacy will be measured using the Newest Vital Sign ${ }^{41}$ and patient activation with the Patient Activation Measure. ${ }^{42}{ }^{43}$ Multimorbidity will be evaluated with the Disease Burden Morbidity Assessment by self-report $^{4445}$ and quality of life, using the SF-12v2. ${ }^{46} 47$

\section{Data and statistical analyses plan}

In the first step, the qualitative data will be analysed by the research assistants and principal investigators according to a qualitative content analysis process in three iterative steps, to identify emerging themes and trends: data reduction, data organisation (matrix-schemes) and their interpretation. ${ }^{48}$ The evolving context and inability to control the environment in which the programmes will be evaluated render the use of an experimental design inappropriate to evaluate quantitative effects (use of services and quality of life). ${ }^{22} 49$ Rather than aim to perform a non-biased estimation of the extent of the effects of CM programmes, the quantitative data will first be analysed, then interpreted in integration with the qualitative data. For use of services, we will use an interrupted time series evaluation approach, ${ }^{50}$ where 
monthly measures (12 measures each year) over the year preceding the start-up and during the carrying out of the study will first allow us to perceive trends and their stability over time. ${ }^{51}$ Regression analysis by segment will then allow us to explore a change in trend or level between each study cycle (each year). ${ }^{51}$ For quality of life, we will perform multiple regression analysis for each HSSC linking change (SF12v2at entry-SF12v2one year later) in quality of life (dependant variable) to participant characteristics while introducing the 'cohort' variable $(1,2$ or 3$)$ as an independent variable to explore if year of participation in the programme seems to have an impact on change in quality of life. The quantitative analyses will be performed using the SAS V.9.2 software.

Two strategies will be used to guide the second stage of the data analysis: description and comparison of cases, and integration of qualitative and quantitative data. ${ }^{52}$ We will first proceed with the isolated analyses of each of the four cases using all the qualitative and quantitative data. One case history grouping all the relevant qualitative and quantitative data will be drafted throughout the process for each HSSC, thus allowing us to manage the large amount of qualitative data collected. ${ }^{27}$ Triangulation of data, at the data source level and at the level of the different evaluators, will ensure validity of the case histories and allow us to integrate the two types of data for a better understanding of the results. This triangulation will also ensure a certain coherence with the search for significance of the developmental evaluation approach. ${ }^{33}$ The four case histories will then be used as a basis for the comparison between cases at the end of the study to answer the third research question with the help of descriptive and interpretative multiple level matrixes allowing for systematic comparisons between cases and between the three units of analysis (macro, meso and micro). ${ }^{48}$ Different analytical techniques for the multiple case studies will be used, such as comparison of patterns, search for rival explanations and the construction of explications. ${ }^{27}$ Data management and reduction will be realised with QSR*NVIVO 10 software. All team members will participate in key stages of the analysis to ensure a good interpretation.

\section{POTENTIAL BIASES}

Given the changing environment and the multitude of variables that can influence the measured quantitative variables (use of services, activation, quality of life), it will be difficult to measure the direct impact of the programme using these variables. It is for this reason that the quantitative data will first be analysed, then interpreted in integration with the qualitative data.

A second important concern is external validity. It represents a potential bias if we try to transfer our results to different contexts. However, multiple case studies will allow us to ensure transferability to other contexts, through the theoretical enlightenment provided and the reproducibility of observations in many cases.

\section{ETHICS AND DISSEMINATION}

Informed consent will be obtained from each person recruited for the interviews and group discussions as well as from the patients who complete the questionnaire. Confidentiality will be respected and data will be stored following the rules currently applied with respect to duration and security. All publications will respect confidentiality.

Findings will be disseminated by publications in peerreviewed journals, international, national and regional conferences, and policy and practice partners in local and national government.

\section{STATUS OF THE STUDY}

The full study is expected to last 3 years, from September 2014 to August 2017.

\section{DISCUSSION}

The project will have a lasting impact on $\mathrm{CM}$ programmes of the partner HSSCs. First, because of the developmental evaluation approach, decision-makers were engaged significantly, at an early stage, facilitating knowledge translation. ${ }^{24} 28$ Then, the early and constant feedback to stakeholders will allow us to provide evidence that may positively influence decisions to improve programmes, while at the same time maximising their chances for sustainability. The researchers' role will play out well beyond the data collection and analysis; they will be able to actively intervene to influence the course of the process by informing decision-making and by facilitating learning. ${ }^{33}$ Finally, decision-makers will be able to put forward the characteristics identified in the clienteles and $\mathrm{CM}$ programmes to contribute to a better impact on use of services, quality of life and patient experience.

Considering the organisational and major financial impact of high users of hospital services and considering that $\mathrm{CM}$ is now proposed by many bodies ${ }^{2} 5354$ to better respond to the complex needs of this clientele, the answer to the research question will be of interest to many decision-makers in the healthcare system. This project will provide relevant results, more specifically in regard to characteristics of the clientele and of the programmes contributing to positive impacts on organisations and patients, as this topic remains unanswered in the literature. Many strategies will thus be undertaken during the case study, so that project conclusions can be transferable to other contexts: theoretical enlightenment; reproduction of observations in many cases $;{ }^{27}$ and in depth description of programmes, actors and context. ${ }^{48}$

\section{Author affiliations}

${ }^{1}$ Department of Family Medicine and Emergency Medicine, Université de Sherbrooke, Sherbrooke, Québec, Canada

${ }^{2}$ Department of Health Sciences, Université du Québec à Chicoutimi, Chicoutimi, Québec, Canada

${ }^{3}$ Centre de santé et de services sociaux de Chicoutimi, Chicoutimi, Québec, Canada 
${ }^{4}$ Agence de la santé et de services sociaux du Saguenay-Lac-Saint-Jean, Chicoutimi, Québec, Canada

${ }^{5}$ Department of Community Health, Université de Sherbrooke, Sherbrooke, Québec, Canada

${ }^{6}$ Department of General Practice and Health Services Research, University Hospital Heidelberg, Heidelberg, Germany

${ }^{7}$ Médiamed Technologies, Mont-Saint-Hilaire, Québec, Canada

${ }^{8}$ Departement of Family Medicine, Université McGill, Montréal, Québec, Canada

Acknowledgements The authors thank Susie Bernier for the translation and Isabelle Gaumond for the final revision of the manuscript.

Contributors $\mathrm{CH}, \mathrm{M}-\mathrm{CC}$ and $\mathrm{MC}$ initiated the project and designed the study. $A B$ (implementation analysis), EMC (health literacy), M-FD (statistical analysis), MF (multimorbidity), TF (case management), CL (poverty), JM (healthcare database), PP (participatory research), PR (mental healthcare) and CR (case study) provided specific expertise. All authors contributed to the redaction and approved the final version of the manuscript.

Funding This work is supported by the Canadian Institutes of Health Research (CIHR) grant number 318771.

Competing interests None.

Ethics approval The research protocol was approved by the Ethics Research Boards of the four HSSCs involved (Chicoutimi, Jonquière, Alma and La Baie).

Provenance and peer review Not commissioned; internally peer reviewed.

Open Access This is an Open Access article distributed in accordance with the Creative Commons Attribution Non Commercial (CC BY-NC 4.0) license, which permits others to distribute, remix, adapt, build upon this work noncommercially, and license their derivative works on different terms, provided the original work is properly cited and the use is non-commercial. See: http:// creativecommons.org/licenses/by-nc/4.0/

\section{REFERENCES}

1. Bodenheimer T, Berry-Millett R. Follow the money-controlling expenditures by improving care for patients needing costly services. N Engl J Med 2009;361:1521-3.

2. Department of health. Supporting people with long term conditions: an NHS and social care model to support local innovation and integration. Department of health, 2005.

3. Commission de la réforme des services publics de l'Ontario. Des services publics pour la population ontarienne: cap sur la viabilité et l'excellence. Ottawa: Gouvernement de l'Ontario, 2012.

4. Hansagi $\mathrm{H}$, Olsson M, Sjoberg S, et al. Frequent use of the hospital emergency department is indicative of high use of other health care services. Ann Emerg Med 2001;37:561-7.

5. Chan BT, Ovens HJ. Frequent users of emergency departments. Do they also use family physicians' services? Can Fam Physician 2002;48:1654-60.

6. Byrne M, Murphy AW, Plunkett PK, et al. Frequent attenders to an emergency department: a study of primary health care use, medical profile, and psychosocial characteristics. Ann Emerg Med 2003;41:309-18.

7. Ruger JP, Richter CJ, Spitznagel EL, et al. Analysis of costs, length of stay, and utilization of emergency department services by frequent users: implications for health policy. Acad Emerg Med 2004;11:1311-7.

8. Lee $\mathrm{KH}$, Davenport L. Can case management interventions reduce the number of emergency department visits by frequent users? Health Care Manag (Frederick) 2006;25:155-9.

9. Schoen C, Osborn R, Squires D, et al. New 2011 survey of patients with complex care needs in eleven countries finds that care is often poorly coordinated. Health Aff (Millwood) 2011;30:2437-48.

10. Brewster LR, Rudell LS, Lesser CS. Emergency room diversions: a symptom of hospitals under stress. Issue Brief Cent Stud Health Syst Change 2001:38:1-4.

11. Sutherland D, Hayter M. Structured review: evaluating the effectiveness of nurse case managers in improving health outcomes in three major chronic diseases. J Clin Nurs 2009;18:2978-92.
12. Kumar GS, Klein R. Effectiveness of case management strategies in reducing emergency department visits in frequent user patient populations: a systematic review. J Emerg Med 2013;44:717-29.

13. Althaus $\mathrm{F}$, Paroz S, Hugli $\mathrm{O}$, et al. Effectiveness of interventions targeting frequent users of emergency departments: a systematic review. Ann Emerg Med 2011;58:41-52.e42.

14. Grover CA, Close RJ, Villarreal K, et al. Emergency department frequent user: pilot study of intensive case management to reduce visits and computed tomography. West J Emerg Med 2010;11:336-43.

15. Singh D. Which staff improve care for people with long-term conditions: a rapid review of the literature. London: National Health Service Modernisation Agency, 2005:70.

16. Sweeney L, Halpert A, Waranoff J. Patient-centered management of complex patients can reduce costs without shortening life. $A m \mathrm{~J}$ Manag Care 2007;13:84-92.

17. American Nurses Association. Nursing's social policy statement. Silver Spring, MD: American Nurses Association (ANA), 2010.

18. Freund T, Peters-Klimm F, Rochon J, et al. Primary care practice-based care management for chronically ill patients (PraCMan): study protocol for a cluster randomized controlled trial [ISRCTN56104508]. Trials 2011;12:163.

19. Barlow J, Wright C, Sheasby J, et al. Self-management approaches for people with chronic conditions: a review. Patient Educ Couns 2002;48:177-87.

20. Reilly S, Hughes J, Challis D. Case management for long-term conditions: implementation and processes. Camb J Ageing Soc 2010;30:125-5.

21. Offredy M, Bunn F, Morgan J. Case management in long term conditions: an inconsistent journey? Br J Community Nurs 2009;14:252-7.

22. Craig P, Dieppe P, Macintyre S, et al. Developing and evaluating complex interventions: the new medical research council guidance. BMJ 2008;337:a1655.

23. Ministère de la santé et des services sociaux du Québec. Système de santé et de services sociaux en bref. Secondary Système de santé et de services sociaux en bref. http://www.msss.gouv.qc.ca/ sujets/organisation/en-bref/gouvernance-et-organisation/ reseaux-locaux-de-services

24. Bowen S. Guide d'évaluation dans le domaine de la recherche en santé. Secondary Guide d'évaluation dans le domaine de la recherche en santé. http://www.cihr-irsc.gc.ca/f/documents/kt_Im_ guide_evhr-fr.pdf

25. Chaudoir SR, Dugan AG, Barr CH. Measuring factors affecting implementation of health innovations: a systematic review of structural, organizational, provider, patient, and innovation level measures. Implement Sci 2013;8:22.

26. National Collaboration for Integrated Care and Support. Integrated care and support: our shared commitment. London: National Collaboration for Integrated Care and Support, 2013.

27. Yin RC. Case study research: design and methods. 5th edn. Thousand Oaks, CA: Sage Publications, 2014.

28. Patton MQ. Developmental evaluation: applying complexity concepts to enhance innovation and use. New York: Guilford Press, 2011.

29. Dozois E, Langlois M, Blanchet-Cohen N. DE 201: guide du praticien de l'évaluation évolutive. Montréal: La fondation de la famille J.W. McConnell et l'Institut international des droits de l'enfant et du développement, 2010.

30. Gerring J. Case study research: principles and practices. Cambridge: Cambridge University Press, 2007.

31. Patton MQ. Evaluation for the way we work. The Nonprofit $Q$ 2006;13:28-33.

32. Patton MQ. Utilization-focused evaluation. 4th edn. Thousand Oaks, CA: Sage, 2008.

33. Gamble JAA. A developmental evaluation primer. Montréal: The J. W. McConnell Family Foundation, 2008

34. Champagne F, Brousselle A, Hartz Z, et al. L'analyse de l'implantation. In: Brousselle A, Champagne F, Contandriopoulos A, et al., eds. L'évaluation: concepts et méthodes. Montréal: Presses de l'Université de Montréal, 2011:237-3.

35. Émond A, Charlebois AM. Guide d'élaboration de modèles logiques de programme: agence de santé et de services sociaux de l'Estrie, 2004.

36. Porteous NL. La construction du modèle logique d'un programme. In: Ridde V, Dagenais C. eds. Approches et pratiques en évaluation de programme. 2nd edn. Montréal: Presses de l'Université de Montréal, 2011:89-108.

37. Yin RK, Ridde V. Théorie et pratiques des études de cas en évaluation de programmes. In: Ridde V, Dagenais C, eds. 
Approches et pratiques en évaluation de programmes. Québec: Les Presses de l'Université de Montréal, 2012:177-93.

38. Fortin MF. Fondements et étapes du processus de recherche. Chenelière, 2010.

39. MacQuarrie C. Theoretical saturation. In: Mills AJ, Eurepos G, Wiebe E, eds. Encyclopedia of case study research. Thousand Oaks, CA: Sage, 2010:927-29.

40. Martinson K, O'Brien C. Conducting case studies. In: Wholey JS, Hatry HP, Newcomer KE, eds. Practical program evaluation. New York: Jossey-Bass, 2010:163-81.

41. Weiss BD, Maysm MZ, Martz W, et al. Quick assessment of literacy in primary care: the newest vital sign. Ann Fam Med 2005;3:514-22.

42. Hibbard JH, Mahoney ER, Stockard J, et al. Development and testing of a short form of the patient activation measure. Health Serv Res 2005:40(6 Pt 1):1918-30.

43. Hibbard JH, Stockard J, Mahoney ER, et al. Development of the patient activation measure (PAM): conceptualizing and measuring activation in patients and consumers. Health Serv Res 2004;39(4 Pt 1):1005-26.

44. Bayliss EA, Ellis JL, Steiner JF. Subjective assessments of comorbidity correlate with quality of life health outcomes: Initial validation of a comorbidity assessment instrument. Health Qual Life Outcomes 2005;3:51.

45. Poitras M-E, Fortin M, Hudon C, et al. Validation of the disease burden morbidity assessment by self-report in a French-speaking population. BMC Health Serv Res 2012;12:35.
46. Ware J, Kosinski M, Keller SD. A 12-item short-form health survey: construction of scales and preliminary steps of reliability and validity. Med Care 1996;34:220-33

47. Ware JE, Kosinski M. T-BDMGB. How to Score Version 2 of the SF-12 Health Survey (With a Supplement Documenting Version 1). Lincoln, Rl: Quality Metric Incorporated, 2002.

48. Miles MB, Huberman AM, Saldaña J. Qualitative data analysis: a methods sourcebook. 3rd edn. London: Sage Publications Inc, 2014.

49. Hulscher ME, Laurant MG, Grol RP. Process evaluation on quality improvement interventions. Qual Saf Health Care 2003;12:40-6.

50. Shadish WR, Cook TD, Campbell DT. Experimental and quasi-experimental designs for generalized causal inference. Wadsworth: Cengage Learning, 2002.

51. Wagner AK, Soumerai SB, Zhang F, et al. Segmented regression analysis of interrupted time series studies in medication use research. J Clin Pharm Ther 2002;27:299-309.

52. Yin RC. Case study research: design and methods. 5th edn. Thousand Oaks, CA: Sage Publications, 2013.

53. MSSS. Cadre de référence pour la prévention et la gestion des maladies chroniques physiques en première ligne. Québec: Gouvernement du Québec, 2012.

54. Commissaire à la santé et au bien-être du Québec. État de situation portant sur les maladies chroniques et la réponse du système de santé et de services sociaux. Rapport d'appréciation de la performance du système de santé et de services sociaux. Montréal: Gouvernement du Québec, 2010:26. 